\title{
A fuzzy approach for statistical modeling of operators' performance
}

\author{
Mohammad Hadi Madadi ${ }^{a}$ and Morteza Mahmoudzadeh ${ }^{b^{*}}$
}

aIndustrial Engineering Department, Non-Governmental and Private Higher Education Institution, Alghadir, Tabriz, Iran ${ }^{b}$ Department of Management, Science and Research Branch, Islamic Azad University, Tabriz, Iran

\section{H R O N I C L E}

Article history:

Received: February 1, 2017

Received in revised format: July

6, 2017

Accepted: July 16, 2017

Available online:

July 17, 2017

Keywords:

Statistical process control

Fuzzy logic

Membership functions

Fuzzy control chart

\section{A B S T R A C T}

The aim of this paper is to integrate fuzzy approach into statistical process control in order to provide a comprehensive description of an operator's performance. To this end, all influential factors in quality of a product are simultaneously controlled to assess the performance in each working day. Then a fuzzy $\bar{x}$ chart is used for statistical modeling process during a month. This paper shows that the fuzzy controller chart can provide a good indication to evaluate a person's work performance.

\section{Introduction}

The maintenance of a stable and reasonable level of some process features is the main purpose of quality control in manufacturing (Pearson et al., 2003). Statistical Process Control (SPC) is one of the recognized methods to improve the quality (Lee, 2012). SPC is a set of robust problem solving tools, which is useful to create stability in the process and to improve its efficiency by reducing variability (Montgomery, 2009). Moreover, SPC can be used as a set of tools for managing processes or determining and monitoring the quality of the final product within an organization (Oakland, 2007). Control charts are one of the SPC tools in quality control (Misra, 2008). These control charts are widely used in industries to detect significant deviations from the process features caused by assignable causes (Xie et al., 2012). Control charts for variables are examples of control charts. The variable is a measurable quality characteristics of a product (Veerarajan, 2002). Control charts for variables such as the $\bar{X}-R$ charts, control both process mean value and the process variability (Montgomery, 2009). It should be noted that a variable control chart can only control a quality property at a specified time (Walker, 2008). Definitely, the control of several quality features, at a specified time, using a standard control chart, will be challenging. Here is where we can use a fuzzy control chart that has more flexibility in such cases (Ross, 2004). Fuzzy control chart is used to control processes that have vague and imprecise 
information (Raz \& Wang, 1990). Fuzzy logic has been successfully used in various areas of industrial applications (Chiu \& Chen, 2012). Fuzzy set theory has proven its great capability for representing vague data. Fuzzy logic provides a systematic base to handle different issues, which are either ambiguous or not well defined (Gülbay \& Kahraman, 2007). In 1965, the concept of "fuzzy sets" was introduced by Professor Zadeh for the first time as an approach for modeling human reasoning under uncertainly (Du, \& Swamy, 2006). The theory of fuzzy sets can also be used to simulate the productive environments in order to better manage it, when faced with little knowledge (Kuipers, 1989). In a Fuzzy Inference System (FIS), certain input data are converted in fuzzy data by using fuzzification method first. After fuzzification, the rules base are formed. Fuzzy rules base with the data base called knowledge base. In the next step, the decision-making produces fuzzy output data and finally with defuzzification method, these data are converted to final output data (Sivanandam et al., 2006). The followings are examples of researches in the field of fuzzy statistical quality control:

Bradshaw using the theory of fuzzy sets showed that control charts could be created based on a concept of graded conformance (Bradshaw Jr, 1983). He suggests that status exists where a concept of graded conformance might provide a more accurate representation of reality (Bradshaw Jr, 1983). Raz and Wang (1990) proposed two approaches based on fuzzy sets theory in construction of control chart for linguistic data. They showed that the control chart for linguistic data performed better than conventional p chart (Raz \& Wang, 1990). Kanagawa et al. (1993) proposed new linguistic control charts for process average and process variability. Their goal was to estimate the existing probability distribution behind the linguistic data. Kandel et al. (1995) showed that, due to the different theoretical basis, the representativeness of the fuzzy controller overcomes the probabilistic controller in simulation of the expert's knowledge. Rowlands and Wang (2000) integrated fuzzy logic and control charts to create and to design a Fuzzy-SPC evaluation. Their control method based on the application of fuzzy logic to the SPC zone rules in order to combine traditional SPC methodology with an intelligent system approach (Rowlands $\&$ Wang, 2000). Taleb and Limam (2002) discussed different procedures of constructing control charts for linguistic data, based on fuzzy and probability theory. They suggested, contrary to the conclusions of Raz and Wang (1990), the choice of degree of fuzziness affected the sensitivity of control charts (Taleb \& Limam, 2002). Tannock (2003) described a simple method for a fuzzy control charting for $\bar{x}$ chart individuals. He used two fuzzy sets, the Centered set and the Random set, to examine the behavior of the fuzzy control chart for three typical unnatural patterns namely; shift, trend and cyclical (Tannock, 2003). Gülbay et al. (2004) developed $\alpha$-cut charts for attributes. Their method gives insight on the capability of detecting the tightness of the inspection by selecting an appropriate $\alpha$-level (the higher $\alpha$ $=$ the tighter inspection) (Gülbay et al., 2004). Cheng (2005) offered a construction of fuzzy control charts for a process under fuzzy outcomes extracted from the subjective quality ratings based on a group of experts. Gülbay and Kahraman (2006) developed fuzzy process control charts and investigated fuzzy unnatural patterns. Their aim was to make an improvement on the control system and exact identification of out-of-control situations, without defuzzification. They implemented an alternative method named Direct Fuzzy Approach to fuzzy control charts (Gülbay \& Kahraman, 2007). They concentrated on the fuzzy comparison techniques named fuzzy mode, fuzzy midrange, fuzzy median and fuzzy average (Gülbay \& Kahraman, 2007). Hsieh et al. (2007) presented a control chart, which uses fuzzy theory and engineering experience to monitor product defects by considering defect clustering. Their proposed control chart could represent better effectiveness than other techniques to reach the on-line control well. Pandurangan and Varadharajan (2011) presented a fuzzy multinomial control chart with variable sample size. They explained that the proposed fuzzy chart was more economic and sensitive in giving the alarm for shift in the specified quality level. Chiu and Chen (2012) proposed a fuzzy system for $\bar{x}$ control chart with variable sampling interval, which could quickly detect the moderate and large shift in sample mean and variance. In general, statistical and fuzzy methods exist to deal with the categorical data (Sorooshian, 2013). 
In this paper, the Fuzzy-SPC, in accordance with Ross's (2004) recommendation, is applied in a practical case. To this end, the performance of an operator in producing the two products is simulated by a fuzzy $\bar{x}$ Chart within 30 days.

\section{Problem description}

Locksmiths Workshop studied here has a variable workload. The majority of products include variety of keys which are implemented for various purposes. One of the activities performed in the workshop, is to provide keys for customers. After a customer's referring and ordering, the desired key is duplicated from a raw key. To description of operator's performance with statistical charts, certain data should be collected. These data are associated with the products to describe the quality of work as well. A good product can be representative of a high accuracy and quality of a production process, and vice versa. This study has focused on two products (key): A-type (Fig 1) and B-type (Fig 2).

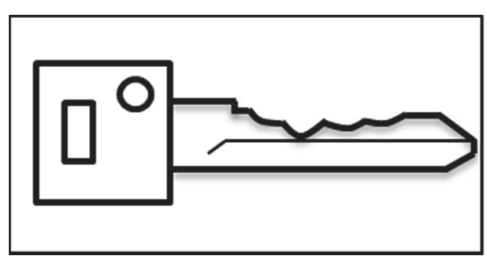

Fig. 1. A-type key

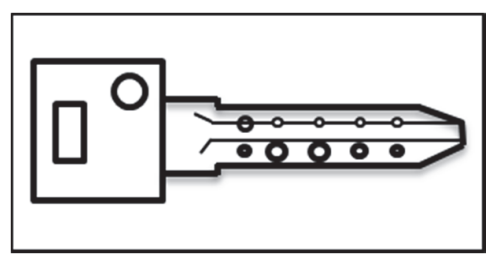

Fig. 2. B-type key

These two products are manufactured in the workshop with the following conditions:

1. In this process, a product (key) is defined as receiving a sample key from the customer and duplicating that from a raw key.

2. The product can be provided from the original or the duplicated sample.

3. Type of product and the volume of its production vary from one working day to another.

4. The product is exclusively made according to customer's order.

5. The number of defects in production, considering the customer's complaints, is determined based on key malfunction.

In this research, product quality depends on several factors. In order to process modeling, first, all the variables influencing on the production of a product must be identified. Second, for each day in every section a mean and a statistical distribution is obtained. Finally, the process will be simulated by producing random numbers in special ranges for 30 working days. To be able to interpret all the variables with a statistical chart, a new approach is applied.

\subsection{Fuzzy Approach}

There are five variables influencing on the procedure of key duplication. Therefore, fuzzy system will have 5 input variables.

- The sample of order that can be an original key or a duplicated key or probability of both.

- The number of orders is determined by customers per each day.

- Machining process includes turning for A-type key (the number of turning) and drilling for Btype key (the amount of applied force in Newton).

- Polishing process which is consisted of polishing time (in seconds) of the product.

- The number of defects which is determined by customer's complaints per each day.

Output variable is as follow: Daily performance which is formed five quality levels from very poor to very well performance.

The form of the fuzzy rules is: 
- If (Sample of Order) is ... and if (Number of Order) is ... and if (Machining Process) is ... and if (Polishing Process) is ... and if (Number of Defect) is ... Then ( Daily Performance) is ...

The obtained results from FIS will be used in a control chart as the daily data.

\subsection{Statistical approach}

In this section, a Shewhart Control chart ( $\bar{X}$ control chart $)$ is used. This chart has a central line and two control limits (Montgomery, 2009). A daily performance is obtained for each product per day. And eventually the average performance is illustrated within 30 days.

\section{Problem Modeling}

\subsection{Fuzzy Modeling}

To create a fuzzy model, each input variable is presented with two fuzzy membership functions. These membership functions are presented with fuzzy numbers. The structure of the input membership functions are shown in Table 1.

\section{Table 1}

Input membership functions

\begin{tabular}{|c|c|c|c|c|}
\hline \multicolumn{5}{|c|}{ First membership function : (a) / Second membership function : (b) } \\
\hline Input variables & key & (a) & (b) & Range \\
\hline Sample of Order & A \& B & original & duplicate & $0-1$ \\
\hline \multirow{2}{*}{ Number of Order } & A & few & many & $0-50$ \\
\hline & $\mathrm{B}$ & few & many & $0-30$ \\
\hline \multirow{2}{*}{ Machining Process } & A & Relatively complete & complete & $2-4$ \\
\hline & $\mathrm{B}$ & detailed & Relatively detailed & $0.6-1.2$ \\
\hline \multirow{2}{*}{ Polishing Process } & A & few & many & $15-25$ \\
\hline & $\mathrm{B}$ & few & many & $10-15$ \\
\hline Number of Defect & A \& B & few & many & $0-5$ \\
\hline
\end{tabular}

The input membership functions are presented by two right triangles that have the same area. For instance, the "sample of order" for input variables is shown in Fig 3. Daily performance of each day is represented by output variable which consists of five fuzzy membership functions as: (a) very bad, (b) bad, (c) reasonable, (d) good and (e) very well. These membership functions are illustrated with five isosceles triangles that have the same area (see Fig 4).

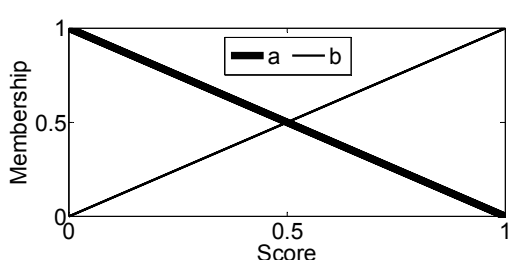

Fig. 3. Fuzzy membership functions for "Sample of Order" (A-type and B-type keys)

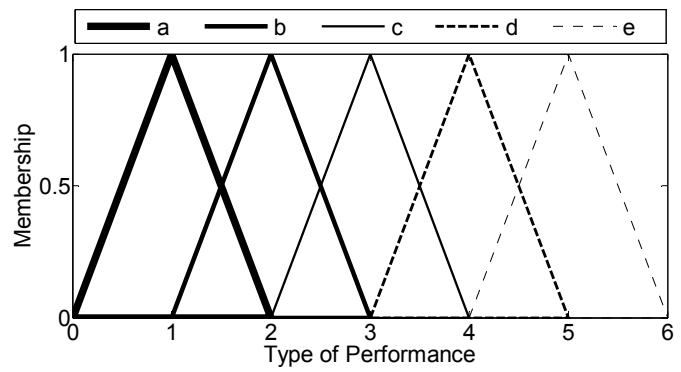

Fig. 4. Output membership functions

The inputs and the output are linked by 32 rules $\left(2^{5}\right)$. A number of fuzzy rules for each product are presented in Tables 2 and 3 and the other rules are given in Appendix A (Tables 6 and 7). 
Table 2

A number of fuzzy rules for A-type key

\begin{tabular}{ccccccc}
\hline Rules & $\begin{array}{c}\text { Sample of } \\
\text { order }\end{array}$ & $\begin{array}{c}\text { Number of } \\
\text { order }\end{array}$ & $\begin{array}{c}\text { Machining } \\
\text { process }\end{array}$ & $\begin{array}{c}\text { Polishing } \\
\text { process }\end{array}$ & $\begin{array}{c}\text { Number of } \\
\text { defect }\end{array}$ & $\begin{array}{c}\text { Daily } \\
\text { performance }\end{array}$ \\
\hline$\bullet$ & original & many & Relatively complete & few & few & Very well \\
$\bullet$ & original & few & Relatively complete & few & few & Good \\
$\bullet$ & duplicate & few & complete & many & few & Reasonable \\
- & original & many & complete & few & many & Bad \\
- & duplicate & few & complete & many & many & Very bad \\
\hline
\end{tabular}

Table 3

A number of fuzzy rules for B-type key

\begin{tabular}{ccccccc}
\hline Rules & $\begin{array}{c}\text { Sample of } \\
\text { order }\end{array}$ & $\begin{array}{c}\text { Number of } \\
\text { order }\end{array}$ & $\begin{array}{c}\text { Machining } \\
\text { process }\end{array}$ & $\begin{array}{c}\text { Polishing } \\
\text { process }\end{array}$ & $\begin{array}{c}\text { Number of } \\
\text { defect }\end{array}$ & $\begin{array}{c}\text { Daily } \\
\text { performance }\end{array}$ \\
\hline$\bullet$ & original & many & Relatively detailed & few & few & Very well \\
$\bullet$ & duplicate & few & Relatively detailed & many & few & Good \\
$\bullet$ & original & few & Relatively detailed & many & few & Reasonable \\
$\bullet$ & duplicate & many & detailed & many & many & Bad \\
$\bullet$ & original & many & detailed & many & many & Very bad \\
\hline
\end{tabular}

In this paper, a max-min Mamdani inference (Zimmermann, 2001) is used on the rules, and the centroid method is used for defuzzification (Starczewski, 2012).

\subsection{Statistical modeling}

The corresponding $R$ chart is not represented because it cannot provide more information in this case (Cheng, 2005). The analysis of this section is depicted with a $\bar{X}$ chart that is plotted by MINITAB software (Version: 17.1.0). The average of sample, the central line and the control limits are shown respectively in Eqs. (1-3) (Montgomery, 2009).

$$
\begin{aligned}
& \bar{X}=\frac{\sum_{i=1}^{n} x_{i}}{n} \\
& C L=\overline{\bar{X}}=\frac{\sum_{i=1}^{m} \bar{x}_{i}}{m} \\
& U C L=\overline{\bar{X}}+A_{2} \bar{R} / L C L=\overline{\bar{X}}-A_{2} \bar{R}
\end{aligned}
$$

For this study, $\mathrm{n}=2, \mathrm{~m}=30$ and $\mathrm{A}_{2}=1.88$. The range of the sample and the average range are shown respectively in Eqs. (4-5) (Montgomery, 2009).

$$
\begin{aligned}
& R=X_{\text {max }}-X_{\text {min }} \\
& \bar{R}=\frac{\sum_{i=1}^{m} R_{i}}{m}
\end{aligned}
$$

\section{Results}

The FIS using MATLAB software (Version: R2011b) for the first day reveal the following results that are given in Table 4 and Table 5. The rest of results for other days are given in Appendix A (Table 8). 
Table 4

Result of Fuzzy-SPC modeling for A-type key

\begin{tabular}{rcccccc}
\hline Day & $\begin{array}{c}\text { Sample of } \\
\text { order }\end{array}$ & $\begin{array}{c}\text { Number of } \\
\text { order }\end{array}$ & $\begin{array}{c}\text { Machining } \\
\text { process }\end{array}$ & $\begin{array}{c}\text { Polishing } \\
\text { process }\end{array}$ & $\begin{array}{c}\text { Number } \\
\text { of defect }\end{array}$ & $\begin{array}{c}\text { Daily } \\
\text { performance }\end{array}$ \\
\hline 1st & 0.5 & 32 & 2.5 & 16.9 & 0 & 3.77 \\
\hline
\end{tabular}

Table 5

Result of Fuzzy-SPC modeling for B-type key

\begin{tabular}{rcccccc}
\hline Day & $\begin{array}{c}\text { Sample of } \\
\text { order }\end{array}$ & $\begin{array}{c}\text { Number of } \\
\text { order }\end{array}$ & $\begin{array}{c}\text { Machining } \\
\text { process }\end{array}$ & $\begin{array}{c}\text { Polishing } \\
\text { process }\end{array}$ & $\begin{array}{c}\text { Number of } \\
\text { defect }\end{array}$ & $\begin{array}{c}\text { Daily } \\
\text { performance }\end{array}$ \\
\hline 1st & 0 & 23 & 0.8 & 10 & 1 & 3.41 \\
\hline
\end{tabular}

For example, the operator's performance for the A-type product in the first day is good and for B-Type product is reasonable. These calculations are repeated for the remaining days until the daily performance of one month for each product is completed.

The fuzzy $\bar{x}$ Chart in figure 5 shows the average performance of an operator in construction of two products during one month. The diagram shows that the process is under control, so it can be interpreted. According to this chart, the performance is reasonable in some days (fifth, tenth, nineteen, etc.), bad in some days (the fourth, seventh, etc.), and good in some days (the first, eleventh, etc.). The randomness test shows that at the significance level of 0.05 with $p$-value $=0.63$, the points are randomly distributed on the graph (Bajpai, 2009).

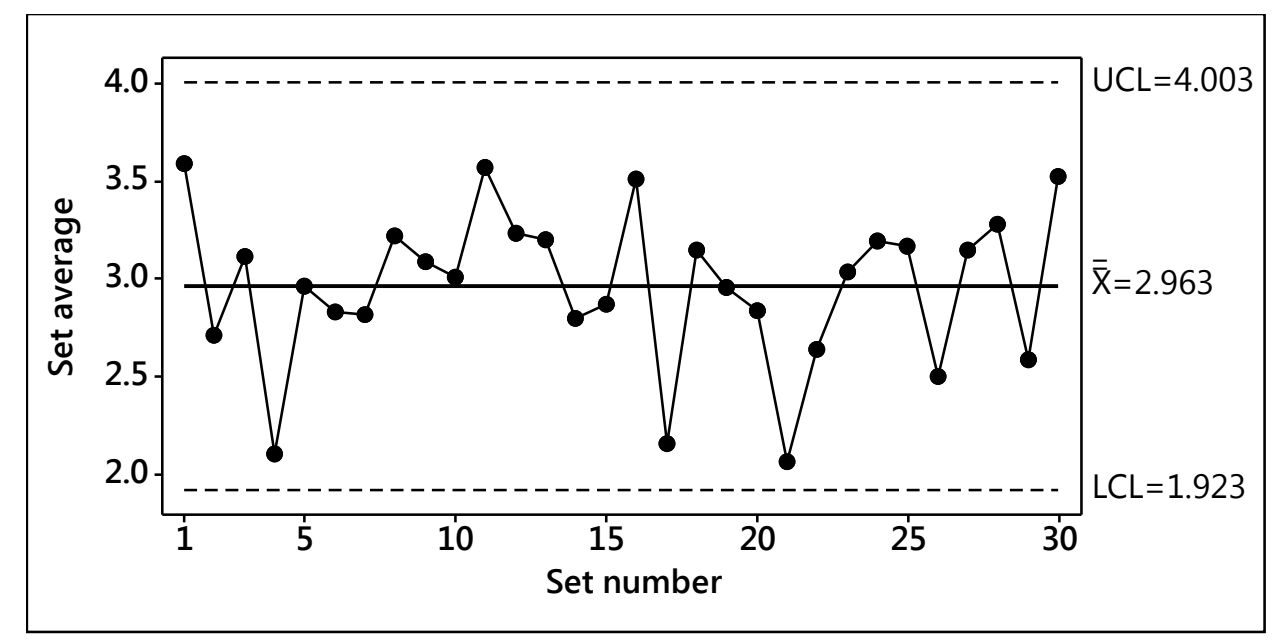

Fig. 5. Fuzzy $\bar{x}$ Chart for Daily Performance

\section{Discussion and Conclusion}

For the purposes of the present study two similar products were manufactured by the same person under specified conditions. The efficiency of the product reflected accuracy and quality of the operations. Operator's performance plays a significant role in both accuracy and quality. Several factors influence the performance of manufacturer. For example, the numbers of defect or finished products can be used to indicate a manufacturer's performance. However, can a high rate of defective products per day be an indication of poor performance or vice versa? Or can we evaluate more purchase orders a privilege for manufacturer, and on the contrary fewer orders as an indication of inefficiency? If the key sample ordered by customer to be copied was already defective, or if fewer number of orders could be attributed 
for spending much time and care by the manufacturer, theses charts would not be sufficiently meaningful. Therefore, in the current study fuzzy approach has been applied to interpret operators' performance during a definite period. Fuzzy system allows control of all influential factors together and present and appropriate output for situation demonstration. We must consider all of the aspects to have a right judgment about people. The results show that the fuzzy approach could be used to evaluate the performance of individuals in various fields. For further research, we propose this method be used to analyze athletes' performances (e.g. soccer players) during a year in order to provide a different criteria for choosing the best athlete of the year (e.g. FIFA World Player of the Year).

\section{References}

Bajpai, N. (2009). Business statistics. Pearson Education India.

Bradshaw, C. W. (1983). A fuzzy set theoretic interpretation of economic control limits. European Journal of Operational Research, 13(4), 403-408.

Cheng, C. B. (2005). Fuzzy process control: construction of control charts with fuzzy numbers. Fuzzy sets and systems, 154(2), 287-303.

Chiu, J. E., \& Chen, B. T. (2012). A Fuzzy System for VSI X-Bar Control Chart. International Journal of Engineering and Technology, 4(4), 427.

Du, K. L., \& Swamy, M. N. (2006). Neural networks in a softcomputing framework. Springer Science $\&$ Business Media.

Gülbay, M., \& Kahraman, C. (2006). Development of fuzzy process control charts and fuzzy unnatural pattern analyses. Computational statistics \& data analysis, 51(1), 434-451.

Gülbay, M., \& Kahraman, C. (2007). An alternative approach to fuzzy control charts: Direct fuzzy approach. Information sciences, 177(6), 1463-1480.

Gülbay, M., Kahraman, C., \& Ruan, D. (2004). $\alpha$-Cut fuzzy control charts for linguistic data. International Journal of Intelligent Systems, 19(12), 1173-1195.

Hsieh, K. L., Tong, L. I., \& Wang, M. C. (2007). The application of control chart for defects and defect clustering in IC manufacturing based on fuzzy theory. Expert Systems with Applications, 32(3), 765-776.

Kanagawa, A., Tamaki, F., \& Ohta, H. (1993). Control charts for process average and variability based on linguistic data. The International Journal of Production Research, 31(4), 913-922.

Kandel, A., Martins, A., \& Pacheco, R. (1995). Discussion: on the very real distinction between fuzzy and statistical methods. Technometrics, 37(3), 276-281.

Kuipers, B. (1989). Qualitative reasoning: modeling and simulation with incomplete knowledge. $A u$ tomatica, 25(4), 571-585.

Lee, G. (2012). Advances in Intelligent Systems. Springer Science \& Business Media.

Misra, K. B. (Ed.). (2008). Handbook of performability engineering. Springer Science \& Business Media.

Montgomery, D. C. (2009). Introduction to statistical quality control. John Wiley \& Sons (New York).

Oakland, J. S. (2007). Statistical process control. Routledge.

Pandurangan, A., \& Varadharajan, R. (2011). Fuzzy multinomial control chart with variable sample size. International Journal of Engineering Science, 3.

Pearson, D. W., Steele, N. C., \& Albrecht, R. (Eds.). (2011). Artificial Neural Nets and Genetic Algorithms: Proceedings of the International Conference in Roanne, France, 2003. Springer Science \& Business Media.

Raz, T., \& Wang, J. H. (1990). Probabilistic and membership approaches in the construction of control charts for linguistic data. Production Planning \& Control, 1(3), 147-157.

Ross, T. J. (2004). Fuzzy logic with engineering applicationsJohn Wiley \& Sons. Inc. New York, US.

Rowlands, H., \& Wang, L. R. (2000). An approach of fuzzy logic evaluation and control in SPC. Quality and Reliability Engineering International, 16(2), 91-98.

Sivanandam, S. N., Sumathi, S., \& Deepa, S. N. (2007). Introduction to fuzzy logic using $M A T L A B$ (Vol. 1). Berlin: Springer. 
Sorooshian, S. (2013). Fuzzy approach to statistical control charts. Journal of Applied Mathematics, 2013.

Starczewski, J. T. (2012). Advanced concepts in fuzzy logic and systems with membership uncertainty (Vol. 284). Springer.

Taleb, H., \& Limam, M. (2002). On fuzzy and probabilistic control charts.International Journal of Production Research, 40(12), 2849-2863.

Tannock, J. D. T. (2003). A fuzzy control charting method for individuals.International Journal of Production Research, 41(5), 1017-1032.

Veerarajan, T. (2008). Probability, Statistics and Random Processes. Tata McGraw-Hill.

Walker, H. F., ElshennawY, A. K., Gupta, B. C., \& Vaughn, M. M. (2012).The certified quality inspector handbook. ASQ Quality Press.

Xie, M., Goh, T. N., \& Kuralmani, V. (2012). Statistical models and control charts for high-quality processes. Springer Science \& Business Media.

Zimmermann, H. J. (2011). Fuzzy set theory — and its applications. Springer Science \& Business Media.

\section{Appendix A}

Table 6

Fuzzy rules for A-type key

\begin{tabular}{|c|c|c|c|c|c|c|}
\hline Rules & $\begin{array}{c}\text { Sample of } \\
\text { order }\end{array}$ & $\begin{array}{c}\text { Number of } \\
\text { order }\end{array}$ & $\begin{array}{c}\text { Machining } \\
\text { process }\end{array}$ & $\begin{array}{l}\text { Polishing } \\
\text { process }\end{array}$ & $\begin{array}{c}\text { Number of } \\
\text { defect }\end{array}$ & $\begin{array}{c}\text { Daily } \\
\text { performance }\end{array}$ \\
\hline 1 & original & few & Relatively complete & few & few & Good \\
\hline 2 & original & few & Relatively complete & few & many & $\mathrm{Bad}$ \\
\hline 3 & original & few & Relatively complete & many & few & Reasonable \\
\hline 4 & original & few & Relatively complete & many & many & Very bad \\
\hline 5 & original & few & complete & few & few & Reasonable \\
\hline 6 & original & few & complete & few & many & Very bad \\
\hline 7 & original & few & complete & many & few & Reasonable \\
\hline 8 & original & few & complete & many & many & Very bad \\
\hline 9 & original & many & Relatively complete & few & few & Very well \\
\hline 10 & original & many & Relatively complete & few & many & Reasonable \\
\hline 11 & original & many & Relatively complete & many & few & Good \\
\hline 12 & original & many & Relatively complete & many & many & $\mathrm{Bad}$ \\
\hline 13 & original & many & complete & few & few & Good \\
\hline 14 & original & many & complete & few & many & $\mathrm{Bad}$ \\
\hline 15 & original & many & complete & many & few & Good \\
\hline 16 & original & many & complete & many & many & Very bad \\
\hline 17 & duplicate & few & Relatively complete & few & few & Very well \\
\hline 18 & duplicate & few & Relatively complete & few & many & Reasonable \\
\hline 19 & duplicate & few & Relatively complete & many & few & Good \\
\hline 20 & duplicate & few & Relatively complete & many & many & $\mathrm{Bad}$ \\
\hline 21 & duplicate & few & complete & few & few & Good \\
\hline 22 & duplicate & few & complete & few & many & $\mathrm{Bad}$ \\
\hline 23 & duplicate & few & complete & many & few & Reasonable \\
\hline 24 & duplicate & few & complete & many & many & Very bad \\
\hline 25 & duplicate & many & Relatively complete & few & few & Very well \\
\hline 26 & duplicate & many & Relatively complete & few & many & Reasonable \\
\hline 27 & duplicate & many & Relatively complete & many & few & Good \\
\hline 28 & duplicate & many & Relatively complete & many & many & Reasonable \\
\hline 29 & duplicate & many & complete & few & few & Very well \\
\hline 30 & duplicate & many & complete & few & many & Reasonable \\
\hline 31 & duplicate & many & complete & many & few & Good \\
\hline 32 & duplicate & many & complete & many & many & $\mathrm{Bad}$ \\
\hline
\end{tabular}


Table 7

Fuzzy rules for B-type key

\begin{tabular}{|c|c|c|c|c|c|c|}
\hline Rules & $\begin{array}{c}\text { Sample of } \\
\text { order }\end{array}$ & $\begin{array}{c}\text { Number of } \\
\text { order }\end{array}$ & $\begin{array}{c}\text { Machining } \\
\text { process }\end{array}$ & $\begin{array}{c}\text { Polishing } \\
\text { process }\end{array}$ & $\begin{array}{c}\text { Number of } \\
\text { defect }\end{array}$ & $\begin{array}{c}\text { Daily } \\
\text { performance }\end{array}$ \\
\hline 1 & original & few & detailed & few & few & Good \\
\hline 2 & original & few & detailed & few & many & $\mathrm{Bad}$ \\
\hline 3 & original & few & detailed & many & few & Reasonable \\
\hline 4 & original & few & detailed & many & many & Very bad \\
\hline 5 & original & few & Relatively detailed & few & few & Reasonable \\
\hline 6 & original & few & Relatively detailed & few & many & Very bad \\
\hline 7 & original & few & Relatively detailed & many & few & Reasonable \\
\hline 8 & original & few & Relatively detailed & many & many & Very bad \\
\hline 9 & original & many & detailed & few & few & Very well \\
\hline 10 & original & many & detailed & few & many & Reasonable \\
\hline 11 & original & many & detailed & many & few & Good \\
\hline 12 & original & many & detailed & many & many & $\mathrm{Bad}$ \\
\hline 13 & original & many & Relatively detailed & few & few & Good \\
\hline 14 & original & many & Relatively detailed & few & many & Bad \\
\hline 15 & original & many & Relatively detailed & many & few & Good \\
\hline 16 & original & many & Relatively detailed & many & many & Very bad \\
\hline 17 & duplicate & few & detailed & few & few & Very well \\
\hline 18 & duplicate & few & detailed & few & many & Reasonable \\
\hline 19 & duplicate & few & detailed & many & few & Good \\
\hline 20 & duplicate & few & detailed & many & many & Bad \\
\hline 21 & duplicate & few & Relatively detailed & few & few & Good \\
\hline 22 & duplicate & few & Relatively detailed & few & many & Bad \\
\hline 23 & duplicate & few & Relatively detailed & many & few & Reasonable \\
\hline 24 & duplicate & few & Relatively detailed & many & many & Very bad \\
\hline 25 & duplicate & many & detailed & few & few & Very well \\
\hline 26 & duplicate & many & detailed & few & many & Reasonable \\
\hline 27 & duplicate & many & detailed & many & few & Good \\
\hline 28 & duplicate & many & detailed & many & many & Reasonable \\
\hline 29 & duplicate & many & Relatively detailed & few & few & Very well \\
\hline 30 & duplicate & many & Relatively detailed & few & many & Reasonable \\
\hline 31 & duplicate & many & Relatively detailed & many & few & Good \\
\hline 32 & duplicate & many & Relatively detailed & many & many & $\mathrm{Bad}$ \\
\hline
\end{tabular}


Table 8

Result of Fuzzy-SPC modeling for A-type \& B-type keys

\begin{tabular}{|c|c|c|c|c|c|c|c|c|c|c|c|c|}
\hline \multicolumn{13}{|c|}{ A-type key=A \& B-type key=B } \\
\hline \multirow{2}{*}{$\begin{array}{c}\text { Day } \\
\text { A\&B }\end{array}$} & \multicolumn{2}{|c|}{$\begin{array}{c}\text { Sample of } \\
\text { order }\end{array}$} & \multicolumn{2}{|c|}{ Number of order } & \multicolumn{2}{|c|}{ Machining process } & \multicolumn{2}{|c|}{$\begin{array}{c}\text { Polishing } \\
\text { process }\end{array}$} & \multicolumn{2}{|c|}{ Number of defect } & \multicolumn{2}{|c|}{$\begin{array}{c}\text { Daily } \\
\text { performance }\end{array}$} \\
\hline & $\mathbf{A}$ & B & $\mathbf{A}$ & B & $\mathbf{A}$ & B & A & B & $\mathbf{A}$ & B & A & B \\
\hline 1 & 0.5 & 0.0 & 32 & 23 & 2.5 & 0.8 & 16.9 & 10.0 & 0 & 1 & 3.77 & 3.41 \\
\hline 2 & 0.4 & 0.0 & 38 & 10 & 3.2 & 0.6 & 17.9 & 13.5 & 3 & 4 & 2.93 & 2.49 \\
\hline 3 & 0.3 & 1.0 & 2 & 17 & 3.4 & 0.6 & 22.0 & 13.6 & 0 & 3 & 3.39 & 2.84 \\
\hline 4 & 0.5 & 0.3 & 31 & 8 & 3.6 & 0.7 & 22.5 & 15 & 5 & 5 & 2.20 & 2.02 \\
\hline 5 & 0.7 & 0.3 & 50 & 13 & 2.3 & 0.8 & 15.0 & 12.1 & 4 & 3 & 3.07 & 2.86 \\
\hline 6 & 0.0 & 0.8 & 32 & 9 & 2.3 & 0.8 & 21.6 & 14 & 2 & 4 & 3.10 & 2.56 \\
\hline 7 & 0.4 & 0.2 & 22 & 2 & 3.3 & 0.7 & 17.8 & 13.5 & 4 & 1 & 2.64 & 2.99 \\
\hline 8 & 0.3 & 1.0 & 11 & 2 & 3.4 & 0.7 & 22.5 & 13.6 & 1 & 0 & 3.10 & 3.34 \\
\hline 9 & 0.0 & 0.0 & 26 & 18 & 3.3 & 0.7 & 21.4 & 14.0 & 2 & 2 & 3.07 & 3.11 \\
\hline 10 & 0.0 & 1.0 & 26 & 30 & 3.8 & 0.9 & 16.5 & 15.0 & 0 & 5 & 3.52 & 2.50 \\
\hline 11 & 1.0 & 1.0 & 44 & 27 & 2.2 & 1.0 & 17.5 & 11.5 & 1 & 1 & 3.65 & 3.49 \\
\hline 12 & 0.5 & 0.5 & 15 & 21 & 2.4 & 1.0 & 19.7 & 12.6 & 1 & 2 & 3.34 & 3.12 \\
\hline 13 & 1.0 & 1.0 & 5 & 19 & 4.0 & 1.1 & 15.4 & 11.3 & 1 & 4 & 3.45 & 2.95 \\
\hline 14 & 0.0 & 0.0 & 12 & 6 & 4.0 & 0.8 & 23 & 10.8 & 4 & 1 & 2.49 & 3.11 \\
\hline 15 & 0.4 & 1.0 & 20 & 8 & 2.8 & 0.6 & 25.0 & 13.1 & 4 & 1 & 2.58 & 3.16 \\
\hline 16 & 0.7 & 0.7 & 3 & 3 & 2.3 & 1.0 & 22.1 & 14.5 & 1 & 0 & 3.38 & 3.64 \\
\hline 17 & 0.0 & 0.0 & 16 & 28 & 2.5 & 0.6 & 20.4 & 15.0 & 2 & 5 & 3.00 & 1.32 \\
\hline 18 & 0.0 & 0.7 & 17 & 2 & 3.2 & 1.0 & 16.2 & 13.3 & 4 & 0 & 2.60 & 3.69 \\
\hline 19 & 0.5 & 0.7 & 30 & 25 & 3.0 & 1.0 & 25.0 & 14.9 & 3 & 2 & 2.80 & 3.11 \\
\hline 20 & 0.0 & 0.0 & 17 & 10 & 3.1 & 0.6 & 16.3 & 11.8 & 4 & 1 & 2.60 & 3.08 \\
\hline 21 & 0 & 0.0 & 40 & 27 & 4 & 1.0 & 24 & 14.2 & 5 & 3 & 1.33 & 2.81 \\
\hline 22 & 0.2 & 0.7 & 48 & 28 & 3.3 & 0.9 & 16.0 & 14.5 & 5 & 2 & 2.27 & 3.01 \\
\hline 23 & 0.3 & 1.0 & 10 & 25 & 4.0 & 0.7 & 23.0 & 10.1 & 3 & 2 & 2.68 & 3.39 \\
\hline 24 & 0.7 & 0.2 & 37 & 12 & 2.0 & 0.8 & 15.2 & 13.3 & 1 & 3 & 3.51 & 2.88 \\
\hline 25 & 0.0 & 0.0 & 2 & 3 & 2.7 & 0.6 & 20.3 & 13.3 & 0 & 1 & 3.47 & 2.87 \\
\hline 26 & 0.3 & 0.4 & 32 & 28 & 3.5 & 1.2 & 15.0 & 13.5 & 4 & 5 & 2.60 & 2.41 \\
\hline 27 & 0 & 0.0 & 8 & 15 & 2.5 & 0.7 & 17.5 & 13.1 & 0 & 4 & 3.72 & 2.58 \\
\hline 28 & 1.0 & 0.0 & 37 & 12 & 4.0 & 0.9 & 17.2 & 15.0 & 3 & 0 & 3.11 & 3.45 \\
\hline 29 & 0.0 & 0.2 & 30 & 10 & 3.0 & 0.7 & 18.2 & 14 & 2 & 5 & 3.10 & 2.07 \\
\hline 30 & 0.0 & 0.6 & 44 & 1 & 3.3 & 0.6 & 16.2 & 12.0 & 1 & 0 & 3.46 & 3.58 \\
\hline
\end{tabular}

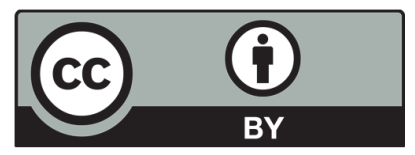

(C) 2017 by the authors; licensee Growing Science, Canada. This is an open access article distributed under the terms and conditions of the Creative Commons Attribution (CC-BY) license (http://creativecommons.org/licenses/by/4.0/). 